\section{Optimization of In Vitro Pecan Pollen Germination}

\author{
Patrick J. Conner \\ University of Georgia-Tifton Campus, Horticulture Department, 4604 Research \\ Way, Tifton, GA 31793
}

Additional index words. Carya illinoinensis, flowering, plant breeding, pollination, rehydration, viability

\begin{abstract}
Storage of pollen from 1 year to the next is often needed to enable desired crosses to be made in a pecan [Carya illinoinensis (Wangenh.) K. Koch] breeding program. Stored pollen is usually tested for viability through the use of in vitro germination tests. An in vitro germination testing system was developed for this purpose using cellophane booklets to provide a solid support for the pollen grains. Optimized germination media contained $5 \%$ sucrose, $20 \%$ polyethylene glycol $8000,0.05 \% \mathrm{Ca}\left(\mathrm{NO}_{3}\right)_{2}, 0.025 \% \mathrm{H}_{3} \mathrm{BO}_{3}$, and $10 \mathrm{~mm}$ 2-( $N$-morpholino)ethanesulfonic acid pH 6.0. Pollen should be rehydrated for 2 to $4 \mathrm{~h}$ in a humidified chamber before germination testing. A germination time of 4 to $24 \mathrm{~h}$ produces similar final germination percentages. Testing of pollen samples stored at $-80{ }^{\circ} \mathrm{C}$ indicates that pecan pollen can be stored for at least 8 years without a decrease in viability. Chemical names used: polyethylene glycol (PEG); 2-( $N$-morpholino)ethanesulfonic acid (MES).
\end{abstract}

Pecan is a wind-pollinated monoecious crop with staminate flowers organized into an ament or catkin and female flowers borne on a spike (Wetzstein and Sparks, 1986). Selfpollination in pecan is usually limited by dichogamy, whereby female and male flowers mature at different times. Pecan cultivars differ with respect to maturity of the staminate and pistillate flowers, leading to both protandrous and protogynous patterns of flowering, termed heterodichogamy. Because of the heterodichogamy of pecan, breeding programs often must make use of stored pollen to achieve particular crosses. Efficient and reproducible viability testing is essential to facilitating the use of stored pollen because nut set cannot be determined until after the end of the flowering season (Sparks and Madden, 1985); thus, the use of nonviable pollen will result in the loss of the cross for the year.

Inadequate numbers of pollinators in pecan orchards can result in reduced crop set and lower yields (Marquard, 1988; Wood, 1997, 2000). In addition, lack of pollinators can result in an increase in self-pollination, which reduces nut set and nut quality (Marquard, 1988; Romberg and Smith, 1946; Wolstenholme, 1969). The development of artificial orchard pollination protocols, especially in western pecan regions where there is a lack of native pecan trees to provide alternative pollen sources, have been investigated (Bennett et al., 1986). Replicable viability tests are crucial to the continued development of artificial pollination and pollen storage protocols.

Germination tests have generally been considered to be the best in vitro indicator of pollen usefulness (Galleta, 1983). The in vitro

Received for publication 19 Jan. 2011. Accepted for publication $11 \mathrm{Feb} .2011$.

e-mail pconner@uga.edu. germination test assesses the viability of a pollen sample by germinating a sample of pollen grains in an artificial media. Through this method it is possible to observe the percentage of pollen grains that develop pollen tubes after a certain period. Methods of in vitro testing vary with the species tested, degree of accuracy desired, and the purposes of the test. Typically, germination media is contained within a hanging drop or well, the media is solidified with agar or gel, or the pollen is germinated on a membrane support.

Pollen germination media must be similar to key components of the stigmatic fluid to produce maximal germination and give a true indication of the viability of the sample. Germination percentage is affected by many factors, including the concentration of $\mathrm{Ca}^{+2}, \mathrm{H}^{+}$, and borate in the germination media (Holdaway-Clarke et al., 2003). The effect of these three ions is not completely understood, but they may interact through changes in the extensibility of pectin in cell walls and appear to be important regulators of pollen tube growth (HoldawayClarke et al., 1997). The addition of boron and calcium to the germination media increases germination percentage and length of pollen tube growth in many fruit species (Galleta, 1983; Kwack, 1965). Optimal concentrations of $\mathrm{Ca}^{+2}$ and borate are high enough to impart rigidity to the pollen tube cell wall to prevent bursting in the face of cell turgor but low enough to allow the wall to stretch quickly during periods of accelerating growth (Holdaway-Clarke et al., 2003). Boron gradients may also be important in directing pollen tube growth toward the ovaries (Blevins and Lukaszewski, 1998). $\mathrm{H}^{+}$promotes more elastic cell walls, perhaps by keeping pectin methyl esterase in a less active state and competing with $\mathrm{Ca}^{+2}$ to reduce pectin crosslinking, leading to a higher degree of pectin esterification and a weaker cell wall (Vervaeke et al., 2005). Sucrose primarily serves to control the osmotic potential of the germination media but may also provide a base for polysaccharide synthesis and metabolic energy (Kwack, 1965). Alternatively, polyethylene glycol (PEG) has been used in some systems to lower the water potential of the media and allow sucrose concentrations to be lowered, producing higher germination rates and/or more stable pollen tubes (Read et al., 1993; Subbaiah, 1984; Vasil, 1987). PEG is relatively inert chemically and cannot enter cells, whereas sucrose enters the pollen and increases already high internal concentrations (Taylor and Hepler, 1997).

Pollen storage and artificial germination protocols for pecan pollen have been investigated. Wetzstein and Sparks (1985) found that fresh pecan pollen could be germinated in a solution of $20 \%$ sucrose and $0.03 \% \mathrm{H}_{3} \mathrm{BO}_{3}$, but pollen germination decreased rapidly during storage with less than $1 \%$ germinating after $5 \mathrm{~d}$ of storage. Yates et al. (1986) optimized the germination solution to $15 \%$ sucrose, $0.05 \%$ $\mathrm{Ca}\left(\mathrm{NO}_{3}\right)_{2}$, and $0.01 \% \mathrm{H}_{3} \mathrm{BO}_{3}$, but also found that pecan pollen loses viability in a matter of days. Yates and Sparks (1989) found that controlled rehydration of dry pollen before placing in the germination media was vital to determining accurate germination rates. Controlled rehydration allows the phospholipids in the plasma membrane bilayer to go through phase transition before being exposed to bulk water (Crowe et al., 1989). Without this transition, the water uptake is rapid and highly damaging to plasma membranes (Dumont-Be'Boux, 1999). The previous lack of hydration of pecan pollen samples before germination tests likely led to the mistaken observation of pollen quickly losing viability when it was simply becoming more desiccated. This is supported by Yates and Sparks (1990) who found that pollen stored for up to 3 years at -80 or $-196^{\circ} \mathrm{C}$ produced fruit set equal to fresh pollen.

Despite these studies, germination tests of pecan pollen carried out in our breeding program and in other pollen physiology studies (L. Lombardini, personal communication) have often produced non-replicable results. We undertook these experiments to develop a pollen germination test that would give more consistent results and could be easily fit into a pecan breeding program.

\section{Materials and Methods}

\section{Collection and storage of pollen}

Catkins were collected from pecan trees at the start of pollen shed. Catkins were laid out on paper in a vacant room to dry and release their pollen over a period of 24 to $48 \mathrm{~h}$. Catkins were then removed from the paper and the pollen was sieved through a No. 140 brass sieve. Pollen was poured into $50-\mathrm{mL}$ polypropylene centrifuge tubes and frozen at $-80^{\circ} \mathrm{C}$ until use. Studies on the pollen germination media were conducted using 'Pawnee' pollen collected in Apr. of 2008. Unless otherwise stated, media composition tests were conducted by removing a pollen sample from the freezer and allowing the tube to thaw overnight at $4{ }^{\circ} \mathrm{C}$ in a dessicator. Pollen samples 
were then rehydrated $4 \mathrm{~h}$ by placing them in a sealed container suspended above a solution of saturated $\mathrm{Cu}\left(\mathrm{SO}_{4}\right)_{2}$ at $20{ }^{\circ} \mathrm{C}$.

\section{Media containers}

Germination media containers were tested using a media consisting of $15 \%$ sucrose, $0.05 \%$ $\mathrm{Ca}\left(\mathrm{NO}_{3}\right)_{2}$, and $0.01 \% \mathrm{H}_{3} \mathrm{BO}_{3}$. Liquid media pollen suspensions were tested in three separate containers, as hanging drops on a glass side, with $100 \mu \mathrm{L}$ placed in a $0.5-\mathrm{mL}$ microfuge tube and in $1 \mathrm{~mL}$ of media in the well of a 12well microplate (Corning Costar 3513, well volume $=6.9 \mathrm{~mL}$; Corning Inc., Corning, NY). Approximately 9000 pollen grains were suspended in each $1 \mathrm{~mL}$ of germination media. Solidified germination media was tested with the addition of $0.4 \%$ agar to the liquid germination media and placing $1 \mathrm{~mL}$ of the media in the well of a 3513 Costar microplate. Media was also tested using the cellophane booklets (Alexandar and Ganeshan, 1989). Booklets consisted of seven layers of filter paper (Fisher P5; Fisher Sci., Pittsburgh, PA) covered by a layer of cellophane (Research Products International Corp., Mount Prospect, IL) and a final single layer of filter paper on top. To use the booklets, the booklet is soaked in germination media until all layers are damp. The top layer of filter paper is then torn off, and the pollen is lightly dusted on top of the cellophane to produce an even layer with few grains touching each other. Booklets are then sealed in petri dishes to prevent drying. After germination was complete, cellophane squares with germinated conidia were removed from the booklet, placed on a glass slide, and fixed and sealed with Permamount mounting fluid (Fisher Sci.) and a glass coverslip. Percentage germinated grains in all tests was determined by examining with a light microscope at $100 \times$ magnification. A grain was considered to have germinated if the pollen tube was equal to or greater in length than the width of the pollen grain.

\section{Media composition}

A starting media consisting of $15 \%$ sucrose, $0.05 \% \mathrm{Ca}\left(\mathrm{NO}_{3}\right)_{2}$, and $0.01 \% \mathrm{H}_{3} \mathrm{BO}_{3}$ was sequentially modified in an attempt to find the optimal media composition. Media was tested using the cellulose booklets described previously.

Media $\mathrm{pH}$. A range of standard buffers was examined in a germination media that consisted of $15 \%$ sucrose, $0.05 \% \mathrm{Ca}\left(\mathrm{NO}_{3}\right)_{2}$, and $0.01 \% \mathrm{H}_{3} \mathrm{BO}_{3}$. A $10 \mathrm{~mm} 4$-(2-hydroxyethyl)-1piperazineethanesulfonic acid (HEPES) buffer was tested at $\mathrm{pH} 7.0,7.5$, and 8.0. A $10 \mathrm{~mm}$ 3-(N-morpholino)propanesulfonic acid (MOPS) buffer was tested at $\mathrm{pH} 6.5,7.0$, and 7.5. A $10 \mathrm{~mm}$ 2-( $N$-morpholino)ethanesulfonic acid (MES) buffer was trialed at $\mathrm{pH} 5.5,6.0$, and 6.5. A $10 \mathrm{~mm}$ tris(hydroxymethyl)aminomethane (tris) buffer was tested at $\mathrm{pH} 7.0,8.0$, and 9.0. A 10 mM potassium phosphate buffer was tested at $\mathrm{pH}$ 6.0, 7.0, 8.0, and 9.0.

Media ion concentration. Calcium nitrate concentration was tested in germination media that consisted of $15 \%$ sucrose, $0.01 \% \mathrm{H}_{3} \mathrm{BO}_{3}$, and $10 \mathrm{~mm}$ MES pH 6.0. Concentrations of $\mathrm{Ca}\left(\mathrm{NO}_{3}\right)_{2}$ tested were $0 \%, 0.01 \%, 0.05 \%$,
$0.1 \%$, and $0.2 \%$. Boric acid concentration was tested in a germination media that consisted of $15 \%$ sucrose, $0.05 \% \mathrm{Ca}\left(\mathrm{NO}_{3}\right)_{2}$, and $10 \mathrm{~mm}$ MES pH 6.0. Concentrations of $\mathrm{H}_{3} \mathrm{BO}_{3}$ tested were $0 \%, 0.01 \%, 0.025 \%, 0.05 \%$, and $0.1 \%$. Potassium nitrate concentration was tested in a germination media that consisted of $15 \%$ sucrose, $0.05 \% \mathrm{Ca}\left(\mathrm{NO}_{3}\right)_{2}, 0.025 \%$ $\mathrm{H}_{3} \mathrm{BO}_{3}$, and $10 \mathrm{~mm}$ MES pH 6.0. Concentrations of $\mathrm{KNO}_{3}$ tested were $0 \%, 0.005 \%, 0.01 \%$, $0.05 \%$, and $0.1 \%$.

Media osmoticum. The potential of PEG to substitute for sucrose as the osmoticum in the germination media was tested in a media that consisted of $0.05 \% \mathrm{Ca}\left(\mathrm{NO}_{3}\right)_{2}, 0.025 \% \mathrm{H}_{3} \mathrm{BO}_{3}$, and $10 \mathrm{~mm}$ MES $\mathrm{pH} 6.0$ to which varying amounts of PEG and sucrose were added. In initial experiments, PEG 400, PEG 1000, PEG 3350 , and PEG 8000 were trialed at 5\%, 10\%, $15 \%$, and $20 \%$ with $0 \%$ and $2 \%$ sucrose. In the second experiment, PEG 8000 was trialed at $0 \%, 10 \%, 20 \%$, and $30 \%$ with sucrose concentrations of $0 \%, 5 \%, 10 \%, 15 \%$, and $20 \%$. In the third experiment, PEG 8000 was trialed at $15 \%$, $20 \%$, and $25 \%$ with sucrose concentrations of $0 \%, 2.5 \%, 5 \%, 7.5 \%$, and $10 \%$.

\section{Rehydration and germination times}

Rehydration times were tested by placing small pollen samples $(\approx 10 \mathrm{mg})$ on a $4-\mathrm{cm}$ square of chemical weighing paper and suspending them $5 \mathrm{~cm}$ above either water or saturated $\mathrm{CuSO}_{4}$ solution in a closed container at $20^{\circ} \mathrm{C}$. Pollen samples were removed after $0,5,30,60$,

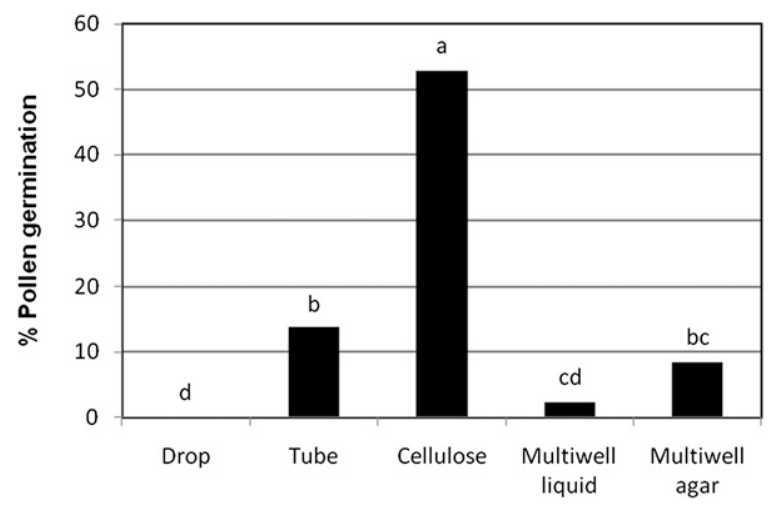

Fig. 1. Effect of media container on pecan pollen germination. Germination media consisted of $15 \%$ sucrose, $0.05 \% \mathrm{Ca}\left(\mathrm{NO}_{3}\right)_{2}$, and $0.01 \% \mathrm{H}_{3} \mathrm{BO}_{3}$. Media was tested on hanging drops on a slide, in a 0.5 $\mathrm{mL}$ microfuge tube with $100 \mu \mathrm{L}$ media, on cellulose booklets, in a multiwall plate with $1 \mathrm{~mL}$ of media, and in a multiwall plate with $1 \mathrm{~mL}$ of media solidified with $0.4 \%$ agar. Pollen in liquid media was tested at 9000 grains $/ \mathrm{mL}$ media. Pollen on the cellulose booklets and solidified agar were lightly dusted so that grains were not touching. Results are the average percentage of germinated pollen grains with 100 grains examined in each of four replications. Mean totals with a common letter are not significantly different $(P<0.05)$.

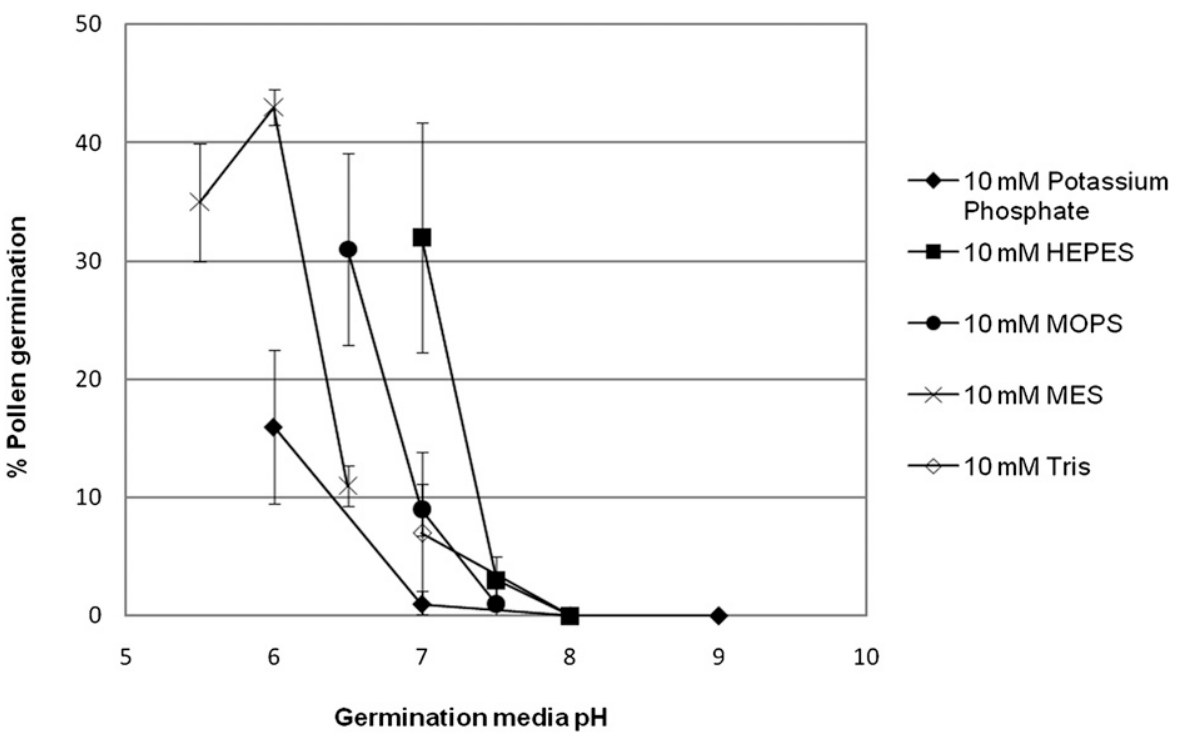

Fig. 2. Effect of germination media buffer on pecan pollen germination. Germination media consisted of $15 \%$ sucrose, $0.05 \% \mathrm{Ca}\left(\mathrm{NO}_{3}\right)_{2}, 0.01 \% \mathrm{H}_{3} \mathrm{BO}_{3}$, and the various buffers. Results are the average percentage of germinated pollen grains with 100 grains examined in each of four replications. Error bars represent the SE of each test. 
120,240 , and $360 \mathrm{~min}$ and germinated on cellophane booklets saturated in a germination media containing 5\% sucrose, $20 \%$ PEG 8000 , $0.05 \% \mathrm{Ca}\left(\mathrm{NO}_{3}\right)_{2}, \quad 0.025 \% \mathrm{H}_{3} \mathrm{BO}_{3}, \quad 0.005 \%$ $\mathrm{KNO}_{3}$, and $10 \mathrm{~mm}$ MES pH 6.0.

Germination time was investigated by rehydrating pollen for $4 \mathrm{~h}$ at $20^{\circ} \mathrm{C}$ and then placing pollen samples on cellophane booklets saturated in a germination media containing $5 \%$ sucrose, $20 \%$ PEG $8000,0.05 \% \mathrm{Ca}\left(\mathrm{NO}_{3}\right)_{2}$, $0.025 \% \mathrm{H}_{3} \mathrm{BO}_{3}, 0.005 \% \mathrm{KNO}_{3}$, and $10 \mathrm{~mm}$ MES pH 6.0. Samples were placed at $20^{\circ} \mathrm{C}$ to germinate and were removed and fixed after 0 , $30,60,120,240,360,720,180$, and $1440 \mathrm{~min}$.

\section{Survey of stored pollen samples}

Stored pollen samples from the breeding program were tested using cellophane booklets and a germination media consisting of 5\% sucrose, 20\% PEG 8000, 0.05\% $\mathrm{Ca}\left(\mathrm{NO}_{3}\right)_{2}$, $0.025 \% \mathrm{H}_{3} \mathrm{BO}_{3}, 0.005 \% \mathrm{KNO}_{3}$, and $10 \mathrm{~mm}$ MES pH 6.0. Pollen samples were collected in April and May of 2000, 2007, and 2008. All samples were stored at $-80^{\circ} \mathrm{C}$ from the time of collection until testing in June 2008.

\section{Data analysis}

All experiments were replicated four times to determine the mean germination percentage. In each replication, 100 pollen grains were examined and those with a pollen tube equal to or greater in length than the width of the pollen grain were considered to have germinated. In the test of media containers, percentage germination results were arcsin transformed and then tested through one-way analysis of variance with mean separation by Duncan's multiple range test. The effect of $\mathrm{Ca}\left(\mathrm{NO}_{3}\right)_{2}, \mathrm{H}_{3} \mathrm{BO}_{3}$, and $\mathrm{KNO}_{3}$ concentration was evaluated using polynomial regression analysis and models were evaluated by $R^{2}$ values. Osmoticum concentration was initially evaluated using a contour plot (Minitab 15; Minitab Inc., State College, PA). Final osmoticum concentrations were evaluated using polynomial regression analysis and models were evaluated by $R^{2}$ values. Correlation between percent germination and $\mathrm{CV}$ in the frozen pollen stocks was evaluated using Pearson product moment correlation coefficients using mean values across treatments.

\section{Results and Discussion}

Germination media containers had a profound effect on the germination percentage of the pollen samples (Fig. 1) as well as the ease with which pollen samples could be evaluated. Cellulose booklets had a much higher germination rate than the liquid or agar solidified media samples. A common problem with liquid media systems is that pollen is often distributed unevenly. Pollen density has been shown to influence the germination of pecan pollen with germination decreasing below or above the optimal concentrations (Yates et al., 1986). However, container shape can influence germination tests by changing the density of the pollen within the media. For example, in the microfuge tube, the pollen would typically sink to the bottom and aggregate together at the tube tip. Even in hanging drop samples, the pollen often migrates to the center of the drop. The cellophane booklets negate this problem by providing a solid support that keeps pollen grains in place.

Read et al. (1993) found that size of the media container did not matter as long as pollen was cultured in films of media 1.3 to $1.7 \mathrm{~mm}$ deep, enhancing aeration. In practice, it can be difficult to handle these thin layers without disrupting growing pollen tubes. The cellophane booklets provide a solid support of cellophane, which overlays a filter paper booklet that serves as reservoir for the media. This system provides good aeration to the pollen grains. It is unclear why the agar-solidified media did not perform better; perhaps there was still too much liquid on top of the agar covering the pollen.

The cellophane booklets greatly simplified the handling and examination of pollen samples. Because the cellophane is clear, it can be mounted directly on a microscope slide, providing a solid support for the pollen grains and their tubes. This is an improvement over liquid samples, which must be handled carefully to prevent the breakage or displacement of pollen tubes. Once fixed on the slide, pollen tubes and grains remain visible for at least 1 year. Because of their ease in handling and improved germination results, cellophane booklets were used in the remaining studies on germination media.

A range of buffer types and $\mathrm{pHs}$ were examined in the germination media. In general, a $\mathrm{pH}$ of 5.5 to 7 seemed to give maximal germination (Fig. 2). Other studies have also found that maximal germination rates are supported over a relatively wide $\mathrm{pH}$ range, usually in the acidic range (Holdaway-Clarke

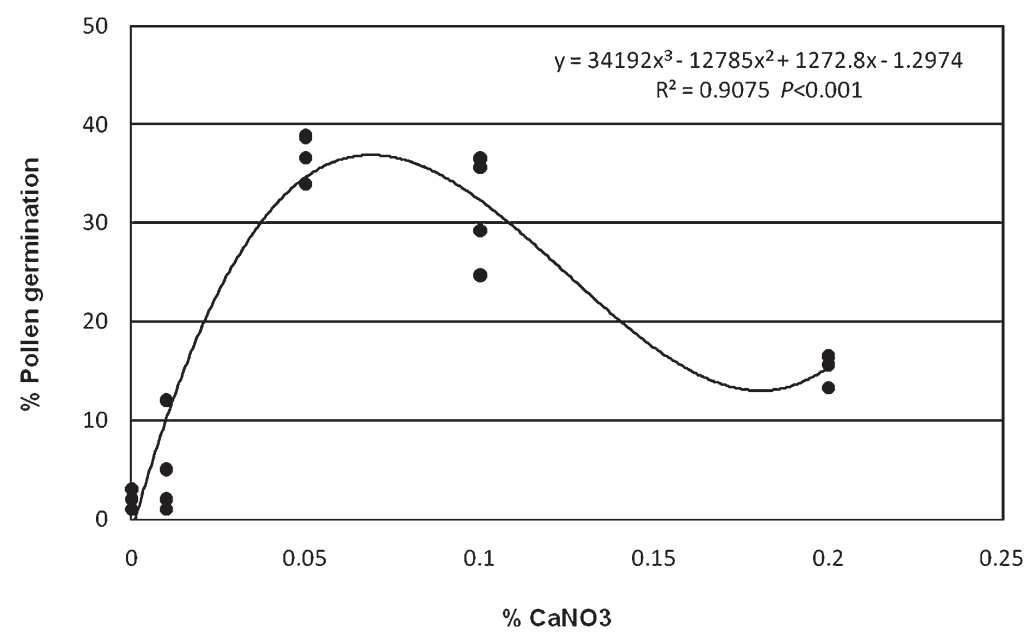

Fig. 3. Effect of germination media calcium nitrate concentration on pecan pollen germination.

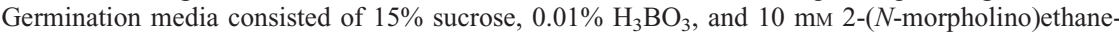
sulfonic acid $\mathrm{pH} 6.0$ plus various concentrations of $\mathrm{Ca}\left(\mathrm{NO}_{3}\right)_{2}$. Each point represents one replication with 100 pollen grains observed per replication.

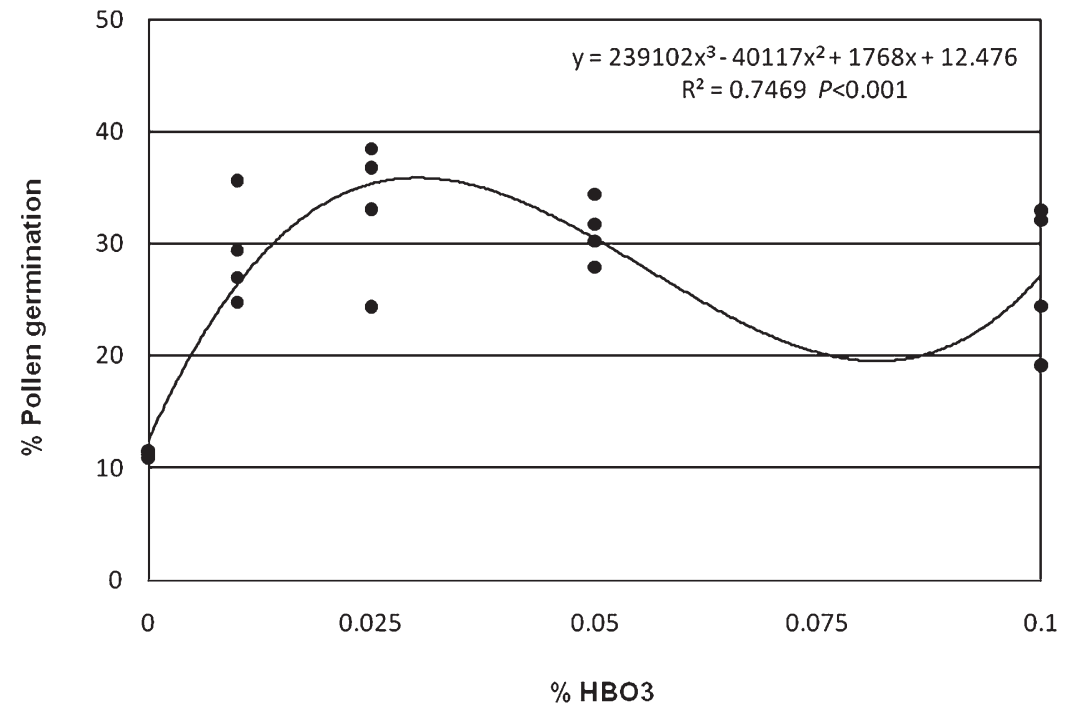

Fig. 4. Effect of germination media boric acid concentration on pecan pollen germination. Germination media consisted of $15 \%$ sucrose, $0.05 \% \mathrm{Ca}\left(\mathrm{NO}_{3}\right)_{2}, 10 \mathrm{~mm} 2-(\mathrm{N}$-morpholino)ethanesulfonic acid $\mathrm{pH}$ 6.0 plus various concentrations of $\mathrm{H}_{3} \mathrm{BO}_{3}$. Each point represents one replication with 100 pollen grains observed per replication. 
et al., 2003; Vervaeke et al., 2005). The effect of $\mathrm{pH}$ was confounded with buffer type in this experiment because buffers vary in their optimal $\mathrm{pH}$ range. Tris and potassium phosphate buffers performed relatively poorly compared with HEPES, MOPS, and MES buffers. Tris buffer chelates needed calcium ions and potassium phosphate buffers generate insoluble calcium phosphate and phosphate ions that can inhibit some enzymes. None of the buffered treatments produced a higher germination rate than the unbuffered control (41\% germination, data not shown). Despite not being significantly better than the unbuffered control, the MES pH 6.0 buffer was used in all subsequent experiments to prevent the $\mathrm{pH}$ variation that might occur in later tests with differing levels of $\mathrm{H}_{3} \mathrm{BO}_{3}$ content and to prevent variation among laboratories with different water $\mathrm{pH}$.

Calcium is important for in vitro pollen germination for both optimal germination rate and in stabilizing pollen tube walls (HoldawayClarke et al., 2003; Kwack, 1965). Normal tube growth can only take place in the presence of a calcium concentration that is situated in a specific range that varies between species (Daher et al., 2009). Germination was almost nil without the addition of calcium in the germination medium (Fig. 3). Germination increased with increasing $\mathrm{Ca}\left(\mathrm{NO}_{3}\right)_{2}$ to $\approx 0.05 \%$ and then declined relatively quickly. This confirmed the rate proposed by Yates et al. (1986) for liquid media. Boron content is generally low in pollen but is often quite high in stigmas and styles (Blevins and Lukaszewski, 1998). Germination increased with increasing boric acid concentration up to $0.025 \%$ and then began a slow decline (Fig. 4). Although there was a low rate of germination without the addition of boron to the germination media, tubes were poorly formed and generally very short. This conforms to the observation of Johri and Vasil (1961) that boron is more critical for pollen tube elongation than for pollen germination. Potassium nitrate has not previously been tested in pecan pollen germination media, but potassium has been found to be a necessary component of germination media in species such as lily and Solanum (Daher et al., 2009). Germination percentage showed a linear decline in increasing rates of $\mathrm{KNO}_{3}$ (Fig. 5). Although not significantly different, there was a slight numerical increase in germination percentage at $0.005 \% \mathrm{KNO}_{3}$ and low rates of $\mathrm{KNO}_{3}$ may be worth further investigation in future studies.

Having the correct osmotic potential in the media is vital for maximal pollen germination. Osmotic potential is commonly controlled by varying the level of sucrose in the germination percentage, but PEG has the advantage of being more inert than sucrose. Initial experiments with four molecular weights of PEG $(400,1000,3350,8000)$ indicated that although PEG 400 produced low rates of pollen germination, the remaining PEG types were very similar to each other (data not shown) and PEG 8000 was chosen for further experimentation. A broad survey of PEG and sucrose concentrations showed that high concentrations of PEG were beneficial when sucrose concentrations declined below 10\% (Fig. 6). Highest germination rates were obtained with PEG rates of $15 \%$ to $25 \%$ and sucrose concentrations of $0 \%$ to $7 \%$ (Fig. 6). Trials of PEG at rates of $15 \%, 20 \%$, and $25 \%$ and $0 \%$ to $10 \%$ sucrose showed that germination increased with increasing rates of sucrose at $15 \%$ PEG (Fig. 7A). At 20\% PEG, germination increased up to $5 \%$ sucrose and then declined (Fig. 7B). At $25 \%$ PEG, germination increased slightly with $2.5 \%$ sucrose and then declined (Fig. 7C). Germination rates were maximal and most stable with 20\% PEG and 5\% sucrose and this rate was used for the remaining studies.

Pollen dehydration occurs just before anthesis and induces a quiescent state that confers resistance to environmental stresses that occur during dispersal. Mature pecan pollen has a moisture content of less than $15 \%$ and proper rehydration of pollen is vital for replicable

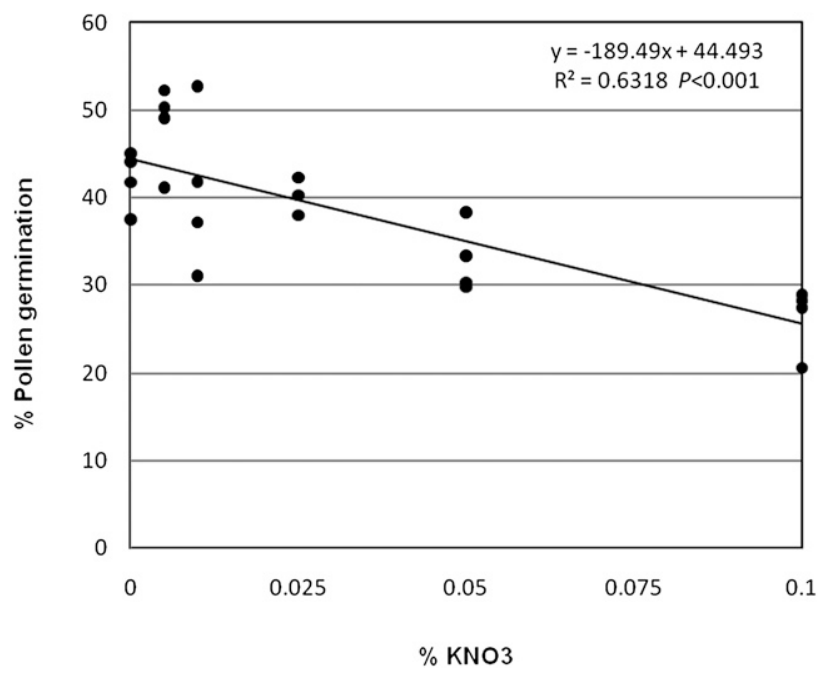

Fig. 5. Effect of germination media potassium nitrate concentration on pecan pollen germination. Germination media consisted of $15 \%$ sucrose, $0.05 \% \mathrm{Ca}\left(\mathrm{NO}_{3}\right)_{2}, 0.025 \% \mathrm{H}_{3} \mathrm{BO}_{3}, 10 \mathrm{~mm} 2-(\mathrm{N}$ morpholino)ethanesulfonic acid $\mathrm{pH} 6.0$ plus various concentrations of $\mathrm{KNO}_{3}$. Each point represents one replication with 100 pollen grains observed per replication.

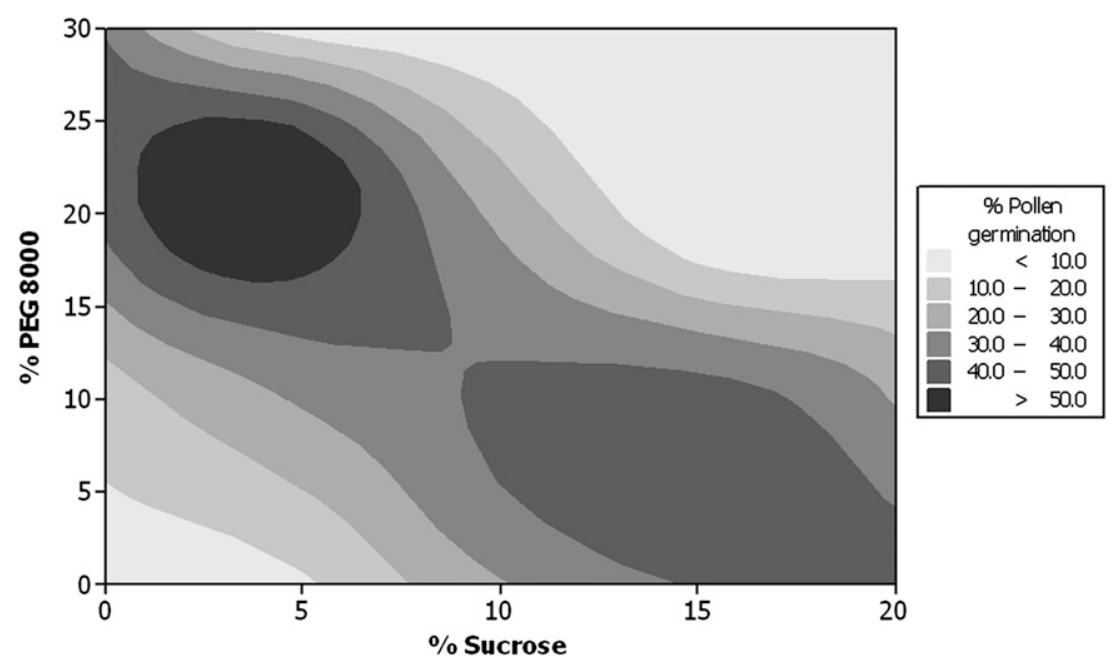

Fig. 6. Contour plot of the effect of osmoticum concentration on pecan pollen germination. Germination media consisted of $0.05 \% \mathrm{Ca}\left(\mathrm{NO}_{3}\right)_{2}, 0.025 \% \mathrm{H}_{3} \mathrm{BO}_{3}, 10 \mathrm{~mm} 2$-( $\mathrm{N}$-morpholino)ethanesulfonic acid $\mathrm{pH}$ 6.0 plus various concentrations sucrose and polyethylene glycol (PEG) 8000 . PEG 8000 was tested at $0 \%, 10 \%, 20 \%$, and $30 \%$ in combination with sucrose at $0 \%, 5 \%, 10 \%, 15 \%$, and $20 \%$. 
A

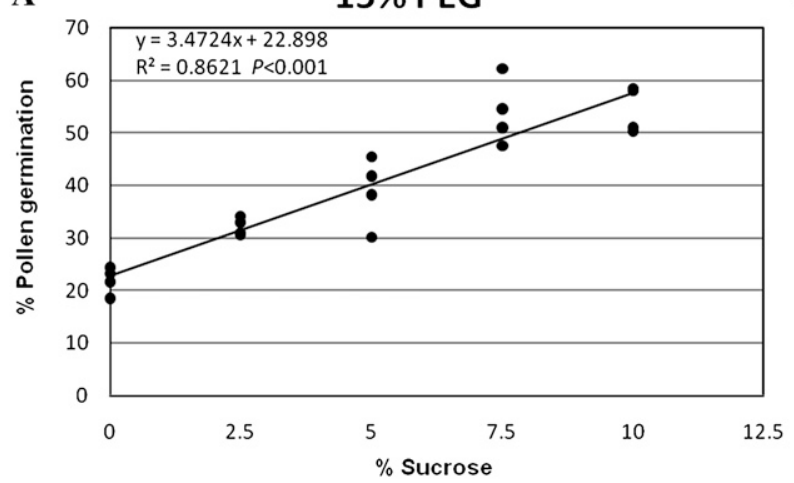

C

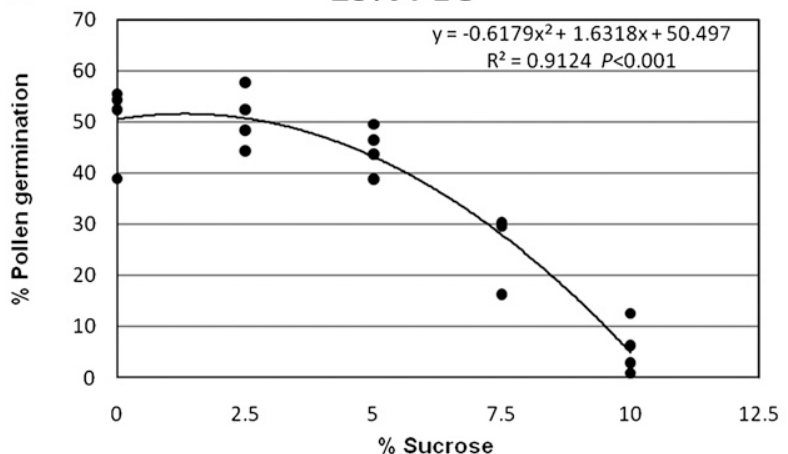

B

$20 \%$ PEG

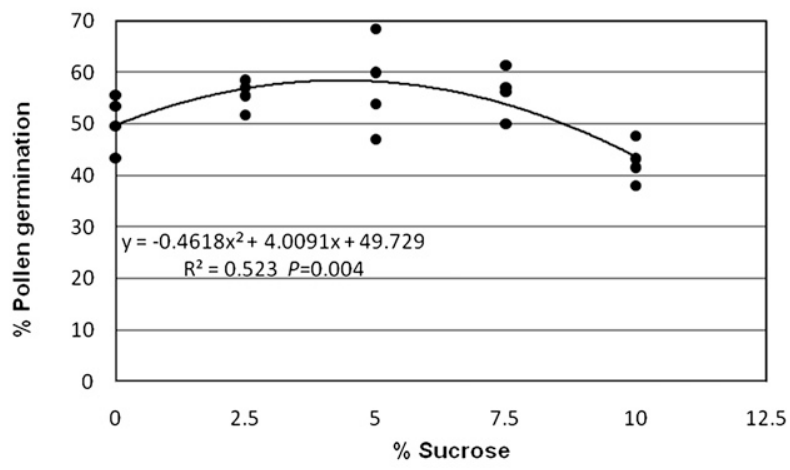

Fig. 7. (A-C) Effect of germination media osmoticum concentration on pecan pollen germination. Germination media consisted of $0.05 \% \mathrm{Ca}\left(\mathrm{NO}_{3}\right)_{2}, 0.025 \%$ $\mathrm{H}_{3} \mathrm{BO}_{3}, 10 \mathrm{~mm}$ 2-( $\mathrm{N}$-morpholino)ethanesulfonic acid $\mathrm{pH} 6.0$ plus various concentrations sucrose and polyethylene glycol 8000 . Each point represents one replication with 100 pollen grains observed per replication.

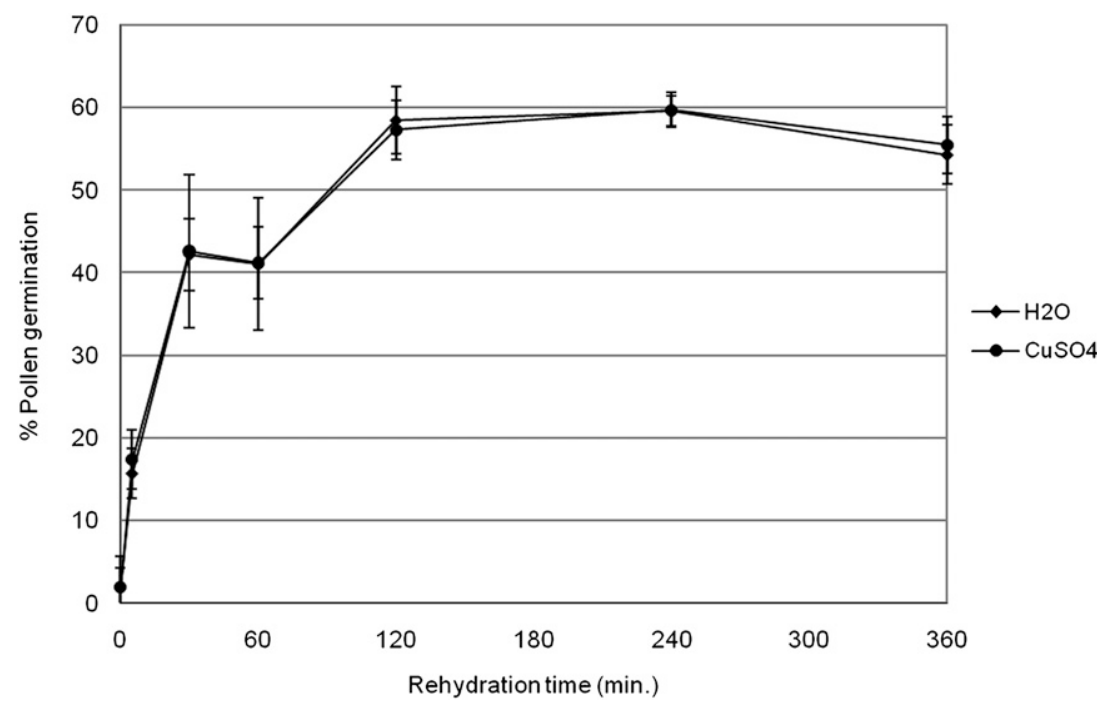

Fig. 8. Effect of rehydration time on pecan pollen germination. Pollen was in a thin layer on weighing paper and suspended above either water or a saturated solution of $\mathrm{CuSO}_{4}$ in a closed container. At the various time intervals, pollen was brought out and tested for germination ability. Germination media consisted of $5 \%$ sucrose, $20 \%$ polyethylene glycol $8000,0.05 \% \mathrm{Ca}\left(\mathrm{NO}_{3}\right)_{2}, 0.025 \% \mathrm{H}_{3} \mathrm{BO}_{3}, 0.005 \%$ $\mathrm{KNO}_{3}$, and $10 \mathrm{~mm} 2-(\mathrm{N}$-morpholino)ethanesulfonic acid $\mathrm{pH}$ 6.0. Results are the average percentage of germinated pollen grains with 100 grains examined in each of four replications. Error bars represent the SE of each test.

examined to determine final germination rate. A germination time of 4 to $24 \mathrm{~h}$ produced similar estimations of germination rate (Fig. 9); thus, as long as the minimum time period is met, time of fixing of the slides is not critical in determination of pollen viability. Using the shorter rehydration period of $2 \mathrm{~h}$, viability of pollen samples can be assessed in as little as $6 \mathrm{~h}$.

The final pollen germination protocol was assessed on a range of pecan pollen samples to assess the variability of the system and the long-term storage potential of pecan pollen samples. Pollen viability ranged from $72 \%$ to $39 \%$ with the highest germination percentage coming from one of the oldest samples (Table 1). Significant differences were detected within sample years $(P=0.049)$ with 2007 having a higher germination percentage $(56.9 \%)$ than 2008 (51.2\%). However, because each year was composed of different cultivars, this difference may be caused more by pollen source than collection year. Importantly, there was no decrease in pollen viability over time. This suggests that pollen samples can be stored for several years for use in crossing in future years. This work confirms the conclusion of Yates and Sparks (1990) that dried pollen may be stored frozen and retain its viability for at least 3 years and contradicts the results of Wetzstein and Sparks (1985), Woodruff (1930), and Yates et al. (1986) that pecan pollen quickly loses viability. The $\mathrm{CV}$ ranged from a low of $1.2 \%$ to a high of $18.2 \%$ and had a mean of $9.3 \%$. There was no correlation between the $\mathrm{CV}$ and the germination percentage in the samples, indicating the test is similarly precise over a range of pollen viability levels.

These results indicate that pecan pollen viability can be estimated quickly and easily through the use of in vitro germination tests. Pollen should be germinated on cellophane supports to prevent the formation of large groups of pollen and to provide adequate aeration. Optimal germination media consists of $5 \%$ sucrose, $20 \%$ polyethylene glycol (PEG $8000), 0.05 \% \mathrm{Ca}\left(\mathrm{NO}_{3}\right)_{2}, 0.025 \% \mathrm{H}_{3} \mathrm{BO}_{3}$, and $10 \mathrm{~mm}$ MES pH 6.0. Pollen should be rehydrated for 2 to $4 \mathrm{~h}$ in a humidified chamber 


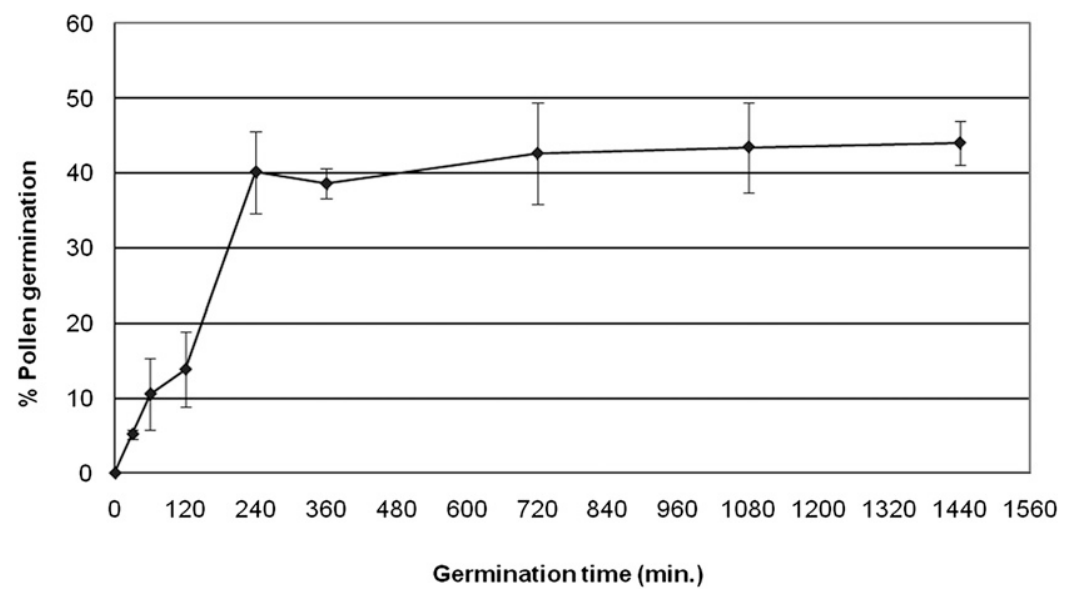

Fig. 9. Effect of germination time on percent germinated pollen. Germination media consisted of 5\% sucrose, $20 \%$ polyethylene glycol $8000,0.05 \% \mathrm{Ca}\left(\mathrm{NO}_{3}\right)_{2}, 0.025 \% \mathrm{H}_{3} \mathrm{BO}_{3}, 0.005 \% \mathrm{KNO}_{3}$, and $10 \mathrm{~mm}$ 2-(N-morpholino)ethanesulfonic acid $\mathrm{pH}$ 6.0. Pollen was placed on cellulose booklets soaked with germination media at $20^{\circ} \mathrm{C}$ for given time intervals, then fixed, and the number of germinated grains was determined. Results are the average percentage of germinated pollen grains with 100 grains examined in each of four replications. Error bars represent the SE of each test.

Table 1. Germination tests of frozen pecan pollen stocks.

\begin{tabular}{|c|c|c|c|c|}
\hline Cultivar & Yr collected ${ }^{\mathrm{z}}$ & Tube no. & $\begin{array}{c}\text { Percent } \\
\text { germination }\end{array}$ & CV (\%) \\
\hline USDA 70-6-15 & 2008 & 1 & 45 & 11.9 \\
\hline USDA $70-6-15$ & 2008 & 2 & 46 & 12.5 \\
\hline USDA $70-6-15$ & 2008 & 3 & 49 & 11.2 \\
\hline Caddo & 2000 & 1 & 39 & 13.7 \\
\hline Caddo & 2008 & 1 & 56 & 12.2 \\
\hline Cherryle & 2007 & 1 & 53 & 10.4 \\
\hline Cherryle & 2008 & 1 & 55 & 2.3 \\
\hline Desirable & 2000 & 1 & 53 & 9.6 \\
\hline Desirable & 2000 & 2 & 50 & 5.4 \\
\hline Desirable & 2007 & 1 & 58 & 7.0 \\
\hline Desirable & 2007 & 2 & 53 & 10.4 \\
\hline Desirable & 2008 & 1 & 56 & 7.5 \\
\hline Excel & 2007 & 1 & 57 & 8.1 \\
\hline Excel & 2007 & 2 & 59 & 18.2 \\
\hline Excel & 2007 & 3 & 59 & 4.7 \\
\hline Excel & 2007 & 4 & 70 & 10.8 \\
\hline Pawnee & 2000 & 1 & 72 & 1.2 \\
\hline Pawnee & 2007 & 1 & 47 & 13.1 \\
\hline Pawnee & 2008 & 1 & 52 & 4.9 \\
\hline
\end{tabular}

${ }^{2}$ Pollen was air-dried in the laboratory, placed in 50-mL polypropolene centrifuge tubes, and then frozen at $-80{ }^{\circ} \mathrm{C}$ until use.

${ }^{\mathrm{y}}$ Germination media consisted of $5 \%$ sucrose, $20 \%$ polyethylene glycol $8000,0.05 \% \mathrm{Ca}\left(\mathrm{NO}_{3}\right)_{2}, 0.025 \%$ $\mathrm{H}_{3} \mathrm{BO}_{3}, 0.005 \% \mathrm{KNO}_{3}$, and $10 \mathrm{~mm} 2$-( $N$-morpholino)ethanesulfonic acid $\mathrm{pH}$ 6.0. Results are the average percentage of germinated pollen grains with 100 grains examined in each of four replications.

before germination tests, and germination rate can be scored from 4 to $24 \mathrm{~h}$ after germination has begun. This protocol should facilitate the use of stored pollen for use in crossing in breeding programs and enable further research into the development of artificial pollination protocols.

\section{Literature Cited}

Alexandar, M. and S. Ganeshan. 1989. An improved cellophane method for in vitro germination of recalcitrant pollen. Stain Technol. 64:225-227.

Bennett, J., T. Koflanovich, and W. Stahmann. 1986. Pecan growers' experiences with artificial pollination. Proc. 20th Western Pecan Conf., New Mexico State Univ. Coop. Ext. Serv. and Western Irrig. Pecan Growers Assn. p. 6-10.
Holdaway-Clarke, T., J. Feijo, G. Hackett, J. Kunkel, and P. Hepler. 1997. Pollen tube growth and the intracellular cytosolic calcium gradient oscillate in phase while extracellular calcium influx is delayed. Plant Cell 9:1999-2010.

Holdaway-Clarke, T., N. Weddle, S. Kim, A. Robi, C. Parris, J. Kunkel, and P. Hepler. 2003. Effect of extracellular calcium, $\mathrm{pH}$ and borate on growth oscillations in Lilium formosanum pollen tubes. J. Expt. Bot. 54:65-72.

Johri, B. and I. Vasil. 1961. Physiology of pollen. Bot. Rev. 27:325-381.

Kwack, B. 1965. The effect of calcium on pollen germination. Proc. Amer. Soc. Hort. Sci. 86:818823.

Marquard, R. 1988. Outcrossing rates in pecan and the potential for increased yields. J. Amer. Soc. Hort. Sci. 113:84-88.

Read, S., A. Clark, and A. Bacic. 1993. Stimulation of growth of cultured Nicotiana tabacum W 38 pollen tubes by polyethylene glycol and $\mathrm{Cu}(\mathrm{II})$ salts. Protoplasma 177:1-14.

Romberg, L. and D. Smith. 1946. Effects of crosspollination, self-pollination, and sib-pollination on the dropping, volume, kernel development of pecan nuts and on the vigor of seedlings. Proc. Amer. Soc. Hort. Sci. 47:130-138.

Sparks, D. and G. Madden. 1985. Pistillate flower and fruit abortion as affected by cultivar, time, and pollination. J. Amer. Soc. Hort. Sci. 110:219223.

Subbaiah, C. 1984. A polyethylene glycol based medium for in vitro germination of cashew pollen. Can. J. Bot. 62:2473-2475.

Taylor, L. and P. Hepler. 1997. Pollen germination and tube growth. Annu. Rev. Plant Physiol. Plant Mol. Biol. 48:461-491.

Vasil, I. 1987. Physiology and culture of pollen. Intl. Rev. Cytol. 107:127-174.

Vervaeke, I., E. Londers, G. Piot, R. Deroose, and M. De Proft. 2005. The division of the generative nucleus and the formation of callose plugs in pollen tubes of Aechmea fasciata (Bromeliaceae) cultured in vitro. Sex. Plant Reprod. 18:9-19.

Wetzstein, H. and D. Sparks. 1985. Structure and in vitro germination of the pollen of pecan. J. Amer. Soc. Hort. Sci. 110:778-781.

Wetzstein, H. and D. Sparks. 1986. Flowering in pecan. Hort. Rev. 8:217-255.

Wolstenholme, B. 1969. Effects of self- and crosspollination on fruit set and nut drop of the pecan at Pietermaritzburg. Agroplantae 1:189-194.

Wood, B. 1997. Source of pollen, distance from pollenizer, and time of pollination affect yields in block-type pecan orchards. HortScience 32: 1182-1185.

Wood, B. 2000. Pollination characteristics of pecan trees and orchards. HortTechnology 1:120-126.

Blevins, J. and K. Lukaszewski. 1998. Boron in plant structure and function. Annu. Rev. Plant Physiol. Plant Mol. Biol. 49:481-500.

Crowe, J.H., F.A. Hoekstra, and L.M. Crowe. 1989. Membrane phase transitions are responsible for imbibitional damage in dry pollen. Proc. Natl. Acad. Sci. USA 86:520-523.

Daher, F., Y. Chebli, and A. Geitmann. 2009. Optimization of conditions for germination of cold-stored Arabidiopsis thaliana pollen. Plant Cell Rep. 28:347-357.

Dumont-Be'Boux, N., B. Anholt, and P. von Aderkas. 1999. In vitro Douglas fir pollen germination: Influence of hydration, sucrose, and polyethylene glycol. Ann. For. Sci. 56:11-18.

Galleta, G. 1983. Pollen and seed management, p. 23-47. In: Moore, J. and J. Janick (eds.). Methods in fruit breeding. Purdue University Press, West Lafayette, IN.

Woodruff, J. 1930. Studies on the staminate inflorescence and pollen of Hicorae pecan. J. Agr. Res. 40:1059-1104.

Yates, I. and D. Sparks. 1989. Hydration and temperature influence in vitro germination of pecan pollen. J. Amer. Soc. Hort. Sci. 114:599605.

Yates, I. and D. Sparks. 1990. Three-year-old pecan pollen retains fertility. J. Amer. Soc. Hort. Sci. 115:359-363.

Yates, I., D. Sparks, K. Connor, and L. Towell. 1991. Reducing pollen moisture simplifies longterm storage of pecan pollen. J. Amer. Soc. Hort. Sci. 116:430-434

Yates, I., T. Thompson, and J. Giles. 1986. Proper pollen storage, germination tests essential to success of artificial pollination. Pecan South 20:23-27. 